\section{What's In This Issue?}

Note from the founding facilitator in chief for Issue 4

Issue 4 of the RRNMF Neuromuscular Journal has lots of great "stuff". My good friend Josh Freeman, MD has an amazing blog on medicine and social justice. I asked Josh if we could begin to publish some of his very thoughtprovoking pieces in the journal and he agreed. The one we are publishing in Issue 4 is called "If you have a hammer..." I am sure you will enjoy these pieces and we plan to run one in each issue if possible in the "What's on Your Mind" section. Josh is a family medicine doc and I think his message is a good one for all of us super-specialists neuromuscular docs. Our hammers are our neuromuscular knowledge and EMG and biopsies and genetics. But we don't have the general overall skillset of a primary care doctor and so it's appropriate that the first encounter a patient has for a medical problem often should be a generalist. Of course, by the time a patient is referred to one of us, they have probably seen a generalist and maybe a surgeon and then a general neurologist, and then us, the neuromuscular specialists! But his point is well taken. And even among us super-specialists, we have different hammers. I remember several years ago, I was in Chile. I was asked to talk to a doctor who had chronic progressive quadriceps weakness. He wanted my opinion on whether this could be due to periodic paralysis. I told him no, it probably was due to IBM. He knew I was an IBM specialist. Then he proceeded to show me the literature he had uncovered on a chronic myopathy that occurs after years of periodic paralysis that is characterized by quadriceps weakness (without finger flexor weakness, of course). I felt embarrassed that I did not know about this condition. He was very nice in his response and said, "Well, you had a hammer and you used it.” My hammer was my knowledge about IBM. So I guess the message is "Beware of the specialists with the hammer. It could be the wrong one!"

I also wrote a piece on the Covid-19 era of telehealth and my telehealth journey from the pre-Covid-19 era when I set up a telehealth ALS clinic between Kansas City and Wichita, Kansas. I was well prepared!

The "New Stuff" section contains a paper by Drs. Nicholas Olney and Richard Olney and colleagues on MUNE as a predictor for progression in ALS. As many of you know, Rick was an international leader in the field of neuromuscular disease, EMG, and ALS. And tragically he died of ALS. This is Rick's last paper and his son Nick, also a neuromuscular neurologist in Portland, Oregon submitted it. I was so glad we could publish this for many, many reasons. Of course, it is good clinical science, but it is also a testament to Rick Olney who we all admired greatly. Thank you Nick for allowing the RRNMF NM Journal to be the home for this publication.

Also in the "New Stuff" section is a paper on Isolated Bulbar ALS, also known as IBALS, by Omar Jawdat, MD and the KUMC group. Even though I am now in Columbia, Missouri at the University of Missouri I am still a part of this group! We believe you can have bulbar ALS that stays confined for at least two years as another "restricted" type of ALS, much like BAD or LAD, of which our group and my earlier group in Texas has published on. If we can understand the factors for why some patients stay restricted for so long we might be able to understand the pathogenesis of ALS to a greater degree. Dr. Stephens and the UCSF neuromuscular group also have a nice paper on how they pivoted their ALS clinic to the virtual mode in response to the Covid-19 pandemic.

In the "Clinical Stuff" section we were pleased to receive a submission by Dr. Heckman and her group in South Africa about myokymia in the setting of neuralgic amyotrophy syndrome (AKA Parsonage-Turner syndrome). Also in the "clinic stuff" category, Dr. Anai Hamasaki, our formal fellow at KUMC who is now at the University of Oklahoma has a nice case of a patient with amyloid myopathy as an IBM mimic. Dr Digala and the group at my new institution at the University of Missouri-Columbia have a case of myasthenia gravis that they believe was triggered by the shingles vaccination.

In the "Looking Back/Looking Forward Stuff" section Dr Todd Levine and colleagues have a great idea on how we can approach small fiber neuropathy in the modern era. The bottom line: Not all small fiber neuropathies are the same!

Finally, I am pleased that the Muscle Study Group (MSG) agreed to have the proceedings and abstracts from this year's virtual meeting published in the journal. We are going to get Issue 4 published just before the meeting which takes place Sept. 25-27, 2020. I believe the launch of this journal brought in a new era of how we communicate in our field. The first virtual meeting of the MSG is another example of how we have to communicate in novel formats.

Enjoy Issue 4!

Rick 